\title{
OS VALORES (BIO)ÉTICOS NA VIDA E NA PRÁTICA DOCENTE
}

\author{
Marcos Alexandre Alves ${ }^{(*)}$
}

\section{INTRODUÇÃO}

A preocupação com a ética está hoje presente em toda sociedade. Não porque lhe seja dedicada maior estima ou particular fidelidade, mas precisamente porque se percebe e se sente a sua falta. Generaliza-se o sentimento de que a vida humana e a sociedade precisam ser revistas à luz da ética, sob pena de se caminhar rumo aos maiores desastres, senão para o completo caos, perdendo a possibilidade de ser feliz e de alimentar a esperança de um mundo de paz e justiça. Como enfrentar a atual carência ética? Pretende-se mostrar que há um caminho que não pode ser negligenciado, quando se busca construir um mundo humano, uma sociedade ética: a educação. Como, porém, educar eticamente? Será que, no campo pedagógico, existe lugar para a questão de ética? A pedagogia poderia ser confrontada com um questionamento e com um engajamento ético? $\mathrm{O}$ objetivo da presente reflexão é analisar a importância da ética no processo educativo, ou seja, intenciona-se investigar a indispensabilidade que assume os valores bioéticos no desenvolvimento responsável do educando, na prática educativa para a formação de um pensar e agir humanos. O que preside as atividades pedagógicas? Qual o princípio imediato que sustenta e exprime a qualidade em educação? Defender-se que a promoção da dimensão ética na educação pela necessidade de reconstruirmos o modo de estabelecimento das relações entre todos os envolvidos no cenário educativo, educadores e educandos, tendo presente as diferentes características do agir humano, radicado na sensibilidade Bioética.

A passagem rápida pelos desafios que emergem da pós-modernidade, confirma a necessidade de encontrar uma nova configuração para a educação e o saber, a fim de se confrontar com um mundo marcado pela primazia do sistêmico. Nesse cenário em que se constata a crise do saber, da subjetividade e do humanismo, cabe a ética, em particular, à Bioética responder e proporcionar com esforço a reconstrução da dimensão crítica do saber humano. Ou seja, ela deve ter

\footnotetext{
${ }^{(*}$ Doutor em Filosofia da Educação Universidade Federal de Pelotas (UFPEL). Mestre em Filosofia prma Universidade Federal de Santa Maria (UFSM). Licenciado em Filosofia pela Faculdade de Filosofia Nossa Senhora Imaculada Conceição (FAFIMC). Professor adjunto do Curso de Filosofia e do Mestrado em Ensino de Humanidades e Linguagens do Centro Universitário Franciscano (UNIFRA).E-mail: maralexalves@gmail.com.
} 
como preocupação fundamental o desenvolvimento de um processo efetivo de humanização. Assim, objetiva-se, nesta investigação, mostrar que a primeira preocupação do processo educativo não pode ser com a mera formação dos funcionários de um sistema vigente, mas com o ato de personalização da pessoa, com o processo de emancipação da liberdade do homem. Trata-se, de dar ao homem um quadro referencial básico, em que ele possa situar-se de modo responsável e livre ao agir no mundo. Qual é o verdadeiro papel da educação no atual momento? E qual a contribuição que a ética pode dar para isto? Ora, pretende-se, aqui, defender que a educação necessária continua sendo aquela que consiste na promoção inadiável da ingenuidade em criticidade, o que implica efetivar em todas as esferas da vida uma atitude ético-crítica. Portanto, educar eticamente é abrir espaço para um procedimento crítico, para a emergência da força de emancipação da razão na vida humana; é desenvolver a criticidade, é capacitar-se a denunciar a desrazão travestida de razão. Uma educação, digno desse nome, é o que alimenta a reflexão questionadora e a responsabilidade em transformar um mundo que se afastou da razão, ou seja, possibilitar ao educando a abertura da vida toda à razão.

\section{ÉTICA COMO FUNDAMENTO DA EDUCAÇÃO}

Para fazer frente aos valores apregoados pela pós-modernidade, o que se está propondo é uma reflexão crítica sobre os fundamentos da educação, que por sua vez não pode mais ser apenas informativa, voltada para o processo ensino-aprendizagem; mas uma educação ética, comprometida com os valores e a construção de uma subjetividade cidadã. A educação não pode servir apenas para ensinar a ler, escrever e contar, senão para formar homens que sejam sujeitos de sua história, e que tenham a possibilidade de desenvolver suas potencialidades, gerando e criando novas condições para ler e compreender o mundo da vida.

A educação enquanto uma prática social incorpora aspectos da Ética, tanto na formação de conceitos como nos próprios embasamentos teóricos necessários à compreensão da prática. Para Imbert (2001), a dimensão ética do ato educativo decorre de sua própria essência. Por ser uma práxis humana, a educação se inclui na esfera de competência ética. Toda educação envolve múltiplas atividades que implicam na aprendizagem de comportamentos, saberes técnicos, organização de hábitos, formação intelectual, internalização de normas e valores sociais. Portanto, a educação pressupõe uma concepção ideal do ser humano.

A educação está comprometida com a formação do indivíduo em todos os sentidos e faz parte de seu funcionamento a inter-relação com todos os segmentos da sociedade, inseridos em 
determinado momento histórico. Nesse sentido, o presente estudo aborda as temáticas da ética e da educação como questões básicas e necessárias à compreensão do embasamento de uma filosofia da educação na prática pedagógica efetivada. Há uma complexidade entre todos esses aspectos abordados, porém essa prática está relacionada com a ética, que se compromete com o desenvolvimento de valores, cujo valor fonte de onde emana e para onde se dirige toda a finalidade de suas ações é a pessoa humana.

Um dos pontos básicos da educação é a questão da liberdade. Ela se apresenta na práxis, na medida em que se funda no saber/fazer, que por sua vez envolve os aspectos da escolha, da decisão, do exercício da liberdade de e para o estabelecimento das condições viáveis de inserção do homem no mundo. Da dialética liberdade/necessidade nascem os valores que conduzirão a conduta do ser humano: o encontro das possibilidades e necessidades individuais com as oportunidades e realidades sociais constituem o cerne do desenvolvimento da inserção do homem no seu meio.

$\mathrm{Na}$ medida em que a educação desenvolve suas atividades voltadas para a formação do educando, ela está comprometida com o valor fonte da educação que é a pessoa humana. $\mathrm{O}$ problema do valor da pessoa humana como ser que age põe-se de tal forma que a ciência se mostra incapaz de resolvê-lo. Esse problema que a ciência exige, mas não resolve, é um problema ético. Entendida a ética como doutrina do valor, do bem e da conduta humana que os visa realizar, ou seja, ela representa uma forma de atualização ou de experiência de valores. Portanto, a ética pode ser vista como uma reflexão crítica sobre a moralidade, sobre o caráter, o modo de ser, a forma de viver, e o comportamento humano, ou seja, sobre o modo como o homem conquista a sua humanidade (VÁSQUEZ, 2002).

A relação de um eu com outro (alteridade) é o fundamento da ética. A pessoa é a medida da individualidade, pois quando um indivíduo se coloca perante outro, respeitando-se reciprocamente, ambos se põem como pessoas, não de maneira abstrata, mas na sua concretitude subjetiva, histórica e cultural.

A essência do ato educativo reside na eticidade. Por ser uma práxis humana, por excelência, a educação se inclui na esfera da ética. $\mathrm{O}$ ato de ensinar/orientar pressupõe um comportamento e uma responsabilidade ética.

O surgimento da Moral decorre a partir do momento em que o homem conquista a natureza social, percebendo-se membro de uma coletividade. Segundo Vásquez (2002), a moral é um fato social, verificando-se somente na sociedade, em correspondência com necessidades sociais e 
cumprindo uma função social, ou seja, um sistema de normas, princípios e valores, que regulamentam as relações mútuas entre os indivíduos ou entre estes e a comunidade, de tal maneira que estas normas, sejam acatadas livres e conscientemente, por uma convicção íntima, e não de uma maneira mecânica, externa ou impessoal.

A vida cotidiana está repleta de escolhas e elas podem ser indiferentes do ponto de vista moral, mas também podem estar moralmente motivadas. Quanto maior é a importância da moralidade, do compromisso pessoal, tanto mais facilmente essa decisão eleva-se acima da cotidianidade.

Toda escolha envolve dilema, por isso gera conflito. A origem de toda a vivência especificamente ética é sempre o conflito. O critério decisivo do conflito reside na vivência do dever que destaca das tendências que vibram em conflito permanente a direção de valor eleita pelo indivíduo e, por isto, ponto de conflito de todas as outras que se encontram em plano inferior. Essas considerações sobre a escolha nos encaminham para a discussão do problema da liberdade, cujo conceito envolve vários enfoques na sua compreensão. Na medida em que ninguém é solitário, a liberdade apresenta-se como um desafio que permeia todos os campos das atividades humanas. A educação envolve tanto a realização individual quanto social, compreendendo o significado das liberdades que existem na comunidade.

A liberdade é um valor que se constitui no fundamento da vida ética. A liberdade ética confere a possibilidade da escolha entre sentidos opostos. A liberdade remeter para a questão da vontade, resultante de uma consciência da obrigação moral, em contraponto ao desejo. Como não podemos atender todos os desejos, a moral surge como um controle do desejo, não como uma repressão, mas como uma conscientização de suas ações e limites.

O homem, somente subordinando os instintos a regras e ideais, transcende ao mundo da natureza podendo considerar-se livre. Ele atua, escolhe, aperfeiçoa-se sempre porque tem consciência de si e de sua finitude. Na medida em que o indivíduo age livremente, o ato moral está sujeito tanto a aprovação, elogio, como a censura ou desaprovação; ele envolve, pois, uma sanção. A liberdade tem um compromisso com a moral social.

A cultura humana resultante da superação do homem como natureza e que tem sua raiz na liberdade remete-nos para a questão dos valores. Toda a ação humana é realizada em vista de um determinado fim, sempre estando ligada a uma forma de valor. O indivíduo quando escolhe e age, está aceitando ou contrariando algo que tem valor. Ao observarmos a existência de valores na 
história, a objetividade desses valores implica um dever, na medida em que, obedecemos a nós mesmos, em nosso significado universal de homens. O dever ser dos valores provém da fonte de que eles se originam.

Os problemas éticos caracterizam-se pela sua generalização, e isto os diferencia dos problemas morais, que se apresentam nas situações concretas. Todas essas situações concretas que propiciam ao homem expor a sua maneira de ser, de viver, de comportar-se, podem ser sintetizadas numa conduta social que é um dos componentes da cultura.

A moral corresponde ao conjunto de regras de conduta admitidas e consideradas como absolutamente válidas em determinadas épocas. Durante grande período da cultura ocidental as regras morais eram entendidas como preceitos tornados válidas por inspiração religiosa. Mais tarde, na época moderna, empreendeu-se um grande esforço para que a moral fosse válida por si mesma, independentemente das religiões. O código moral cristão não representa um código racional, mas nele está o núcleo básico da moral ocidental que é o ideal de pessoa humana. Kant (1997) vai tentar sistematizar os diversos mandamentos do código, formulando o imperativo categórico de se tratar a pessoa como "fim e nunca como puro meio".

No que diz respeito à educação, a pessoa humana segue os compromissos éticos em busca de uma autorealização que ocorre num processo permanente de interação com as demais. Nesse processo, está em jogo a moral como um conjunto de regras e normas que determina como deve ser o comportamento do indivíduo como membro da comunidade e a sua liberdade e consciência de aceitar essas normas. Isso significa que um ato só é moral se passar pelo crivo da aceitação pessoal da norma. A aceitação de um caráter social da moral como predominância nas decisões leva-nos a um dogmatismo e legalismo.

Portanto, busca-se compreender melhor a fundamentação da conduta do indivíduo, procurando os subsídios necessários à formação e de sua cidadania. No momento, em que há uma amplitude do espaço desse indivíduo em termos de ação e decisão, discutir sobre os valores e normas morais torna-se tarefa indispensável no processo educacional. Esta nova dimensão de perceber o "universo" do indivíduo leva-nos a meditar sobre a importância da educação e da necessidade de um referencial ético para dotá-lo das condições básicas para decidir e agir consciente nesse contexto de mudanças rápidas e bruscas. 


\section{ASPECTOS HISTÓRICOS E CONCEITUAIS DA BIOÉTICA}

Historicamente, a Bioética surge a partir das discussões relativas à ética médica, já que dessa última ciência se ergueu o estudo da decisão moral no campo médico. A ética médica centrava-se na relação médico-paciente, na qual o médico decidia tudo, principalmente sobre aquilo que ele acreditava ser bom para o seu paciente. Raramente se levava em consideração os interesses e anseios dos seus pacientes e familiares. Esse tipo de postura, por parte do médico, produz uma espécie de cultura, na área da medicina, que pode ser denominada de paternalista. Esse modelo, em que impera o poder e a autoridade do médico, começa a ser colocado em questão a partir dos anos 1970 por várias causas, como uma abordagem secular, interdisciplinar, prospectiva, global e sistemática.

A abordagem da Bioética se deu, segundo Anjos (2001), por meio de uma dupla tomada consciência: por um lado, teólogos, conscientes de viver em um mundo pluralista, e da necessidade de discutir questões que interessavam a todos os cidadãos, sentiram que não podiam se fechar em uma perspectiva totalmente religiosa, e que precisavam secularizar a sua linguagem e argumentação; e, por outro lado, percebendo sua implicação nas questões discutidas, intervieram médicos, filósofos, juristas, sociólogos, economistas, legisladores e um conjunto de cidadãos. Nessa mesma perspectiva, a Bioética pretende para si, também, uma abordagem interdisciplinar, em que se privilegia a colaboração e a interações das diversas ciências para analisar as questões concretas do mundo da vida e assim encontrar soluções adequadas. Uma terceira característica da Bioética é sua visão prospectiva, pois as regras tradicionais não respondem satisfatoriamente às demandas sociais que são cada vez mais complexas e que demandam novos patamares da discussão e de reflexão, a fim de encontrar soluções adequadas à situação atual e até permissíveis para o futuro.

Essas três características da Bioética viabilizam as condições necessárias para se fazer uma abordagem global e integral da pessoa, da cultura e da sociedade na qual ela está inserida. A Bioética se interessa pela decisão pessoal, pelo diálogo interpessoal, pelas estruturas sociais e legais e pelas regras e valores dados pela sociedade. E, por último, faz uma abordagem sistemática e não se limita a solucionar problemas isolados uns dos outros, sem ligação ou coerência. Portanto, Bioética é, por um lado, uma análise rigorosa e lógica; por outro, busca a coerência na solução de diversos problemas morais (DURAND, 1995).

Atribui-se a Potter (1971) ter cunhado e divulgado a palavra Bioética, em 1971. Inicialmente, o sentido por ele atribuído à Bioética referia-se a importância das ciências biológicas 
na melhoria da qualidade de vida e à sobrevivência do planeta (CLOTET, 2003). Posteriormente, Potter defende que a Bioética é uma nova ética científica, que combina humildade, responsabilidade e competência, numa perspectiva interdisciplinar e intercultural que potencializa o sentido da humanidade. Ou seja, nesse período, Potter defende uma "bioética global, como uma nova ciência ética, é uma necessidade para a sobrevivência a longo prazo" (2001, p. 337). Essa nova racionalidade ética conduz à constituição da subjetividade humana, da formação do homem e do seu projeto de viver, neste mundo, em harmonia consigo mesmo, com os demais e natureza. Nesse sentido, entende-se que a Bioética, pode ser um instrumento a serviço do cultivo do desenvolvimento humano; pode apoiar o homem, despertá-lo e estimulá-lo para que consiga reconhecer-se na sua própria humanidade; pode ajudá-lo a descobrir seu próprio lugar no mundo, a conseguir a estima de si mesmo e assumir a responsabilidade para com o futuro da vida no planeta.

Diante de questões emergentes decorrentes das novas descobertas científicas, no campo da biotecnologia, da clonagem biológica e da problemática ambiental, as respostas oferecidas pela moral não são suficientes: nesse viés situa-se a Bioética. Pode-se entender então que, a reflexão crítica a partir dos fundamentos da Bioética, é provocada e estimulada pelas questões que se apresentam a cada novo conhecimento gerado pelas ciências ou possibilitado pelo uso de novas tecnologias, ou seja, a partir dos problemas que se apresentam no cotidiano social e ambiental.

Atualmente, para Durand (2003), a Bioética é um assunto que perpassa todos os níveis da vida e envolve todos os setores de nossa sociedade, tais como as áreas da saúde, da política, da sociologia, da economia, da ecologia, da educação. Ela faz parte do nosso dia-a-dia, e a sua reflexão começa a interferir sempre mais em nossas vidas. Nesse sentido, a Bioética não quer ser considerada como uma ciência, disciplina ou movimento social, mas uma dinâmica reflexiva que procura resgatar a dignidade da pessoa humana e sua qualidade de vida desde o nível "micro" até o “macro" (POTTER, 1971).

Por conseguinte, ao se trabalhar com questões de Bioética impõe-se ter presente uma análise racional sobre o comportamento humano, isso não implica apenas uma reflexão desvinculada do mundo circundante. $\mathrm{O}$ destinatário desta nova proposta ético-formativo é o homem, porque é ele que constrói sua vida no mundo; é o homem que se desenvolve e amadurece como humano, em harmonia consigo mesmo, com os demais e com a natureza. Os valores éticos nascem ou deixam de nascer no íntimo de cada ser, no seu coração e na sua mente. Desse modo, a Bioética pode ser um instrumento a serviço do cultivo do desenvolvimento humano; pode apoiar o homem, despertá-lo e 
estimulá-lo para que consiga reconhecer-se na sua própria humanidade; pode ajudá-lo a descobrir seu próprio lugar na criação, a conseguir a estima de si mesmo, do outro e da natureza. Portanto, a missão da Bioética é (re)significar o papel dos valores fundamentais na educação, como estímulo potencial para o melhoramento humano no ambiente em que vive, nessa hora da humanidade em que o homem se pergunta pelo sentido de sua passagem na terra.

Nos últimos anos, o mundo mudou rapidamente. A ciência, a tecnologia, a economia, a política e a ideologia, tudo está mudando de maneira vertiginosa, e nessa mudança toda, pela qual passa o mundo, o homem permanece desorientado, tentando reconhecer-se e encontrar valores que orientem o seu pensar e agir como efetivamente humano. Em um mundo de mudanças rápidas, parece que o único consenso, em termo de objetivo, entre os povos é a busca pelo chamado “desenvolvimento" que passa, inevitavelmente, pelo aprimoramento tecnológico e industrial, até aí nenhum problema. No entanto, o problema se manifesta quando esse ideal "desenvolvimentista" aparece como referencial e único estilo de vida, pelo qual o homem poderá atingir o ápice da liberdade pessoal, da modernização e do poder (POTTER, 2001).

A Bioética surge, neste contexto, como uma voz e um alerta para uma reflexão profunda sobre os perigos de uma concepção em que o homem seja educado apenas para produzir e consumir, mais do que para viver uma vida plena e harmônica; para "ter" mais e não para "ser" mais. Nesse sentido, o grande convite feito pela Bioética, neste momento em que o homem se embriaga com os poderes de uma ciência e uma tecnologia que ele mesmo criou, e se sente seduzido pela riqueza, a notoriedade e os prazeres; em que recorre a paraísos artificiais, porque não encontra a si mesmo, vislumbra-se uma tendência para um subjetivismo sadio em que o homem reedita para si, sem sabê-lo, o clássico "conhece-te a ti mesmo"; o homem tenta perguntar-se sobre o "humano". Da mesma forma que o homem se redescobre como ser humano, mesmo que pareça um paradoxo, começa a descobrir a alteridade.

Portanto, a intenção desse texto é demonstrar, a partir da Bioética, a necessidade de uma aproximação e interpenetração da ética, das ciências e as questões ambientais, num esforço sinérgico de busca e reflexão do humano. Há perguntas mais profundas quando se fala do valor da educação e da Bioética, que nós educadores devemos nos colocar com sinceridade: é hoje legítima e realista a aspiração de situar o homem na categoria de pessoa racional, imaginativa, criadora, consciente, reflexiva, cultivada e desenvolvida sobre a individualidade instintivo-animal? Que crianças, jovens e adultos se quer formar: objetos que consomem ou se consomem no desfrute e no 
prazer apenas do material? Ou, sujeitos que harmonizem sua existência e encontrem a felicidade na realidade de seres integrais?

Acredita-se que a Bioética pode apresentar respostas à interrogação do "para quê" da educação e sustentá-las com responsabilidade a partir da (re)significação dos valores éticos fundamentais. Desde as sociedades primitivas houve múltiplas maneiras de se tentar uma educação efetivamente humana. Um projeto concreto para atender a essa problemática deve propor-se a: ensinar sobre culturas dos diferentes com o objetivo de aproximar os homens na mutua compreensão; ensinar também sobre os direitos humanos; por fim, ensinar sobre a urgência de preservar o meio ambiente.

\section{A IMPORTÂNCIA DA ÉTICA NO CAMPO EDUCATIVO}

Hoje, talvez a educação seja o problema mais significativo, na medida em que ela está ligada e comprometida com todas as outras áreas e segmentos que compõem o tecido social. Dela faz parte a realidade, onde o indivíduo se educa e o próprio indivíduo no seu processo de educar-se. Nesse sentido, a educação pode ser considerada um empreendimento ético. Toda a educação se move na tensão polar das categorias: natureza e liberdade, facticidade e sentido, ser e dever ser.

O significado do ser de do dever ser, precisam ser clarificados na educação; há necessidade de entendermos o conceito e a filosofia da educação que sustenta o processo, porque é a partir dela que se instaura a ação pedagógica, na finalidade de auxiliar os objetivos educacionais. Se para Aristóteles (2001) a educação teria a função de promover a aquisição da virtude (areté) ou do bem moral, podemos encontrar em Kant (1999), a conceituação de que a educação é uma ação exercida pelas gerações adultas sobre as gerações que ainda não estão preparadas para a vida social. A diversidade de conceituações permite-nos observar o encaminhamento da questão educacional ao longo de um processo histórico, assim como a relação da Educação com a sociedade, em termos de expectativas, interesses e valores, a partir de suas dimensões políticas, econômicas, sociais e éticas.

A educação envolve os valores que emergem da sociedade e os que decorrem da proposta do educador; esses valores não são vistos como alguma coisa que se quer ou não, mas como um dever ser, no sentido de uma dimensão maior que se caracterize como legítima e pertinente. Segundo Cortina (1996), o elemento ético permeia todo o processo educativo, sendo que a situação identificada por alguns como crise na educação, na verdade pode ser identificada como uma crise de valores na sociedade. 
Nessa crise estão colocados os problemas da própria sociedade e da cultura onde se instala a educação. É por meio da educação que o indivíduo será levado a compartilhar dos acontecimentos sociais. Não se pode falar em educação sem falar da política da e na educação advindas da sociedade. Uma educação emancipada realiza-se no enfrentamento prático da questão dos valores e da questão da coordenação dos planos para a ação coletiva, da formação da vontade política.

Por conseguinte, a educação exige, em um contexto pós-moderno, em que coexistem valores, práticas e comportamentos remanescentes de outras formas de organização, mas que prenunciam uma nova ordem, a revisão das funções de uma prática educacional, sobretudo, ante a questão do sucesso escolar, a evasão dos alunos, a marginalidade educacional, a educação informal, educação e trabalho, entre tantas outras exigências dos novos tempos.

Hoje, qual o desafio que nós educadores temos pela frente? Primazia do sistêmico, do material, do técnico... A primeira preocupação da educação não pode ser com a mera formação dos funcionários de um sistema vigente, mas com o ato de personalização da pessoa. A educação deve proporcionar ao homem um quadro referencial básico onde ele possa situar-se de modo responsável e livre ao agir no mundo.

Qual é verdadeiro papel do ato educativo, no atual momento em que a educação parece perder a batalha contra as forças do interesse material, mesquinho, imediato e consumista? Segundo Arendt (2003), a função do ato educativo, resume-se em humanizar o ser humano. Ou seja, o verdadeiro papel da educação: a) Não se restringe somente à qualificação de um agente para operar na forma que lhe é devida, meramente técnica, mas com seu perfil, capacidades e habilidade enquanto agente humano; b) Não vai depender apenas da fidelidade ao modelo de produção ou de consumo, mas, a fidelidade ao modelo de sociedade e de ser humano que se tem em mente; c) Não poderá ser pensada em termos exclusivos da satisfação da clientela tal qual é, pois o educador trabalha com a perspectiva do sucesso dos educandos; d) Não basta estarem satisfeitos com a Escola. Não é suficiente que estudem somente para satisfazer a um exame ou concurso, nem para exercer uma mera função social ou econômica, mas para se realizarem efetivamente como seres humanos.

Nesse sentido, Alencar (2001) tem razão quando define o ato educativo como um ensinar a olhar para fora e para dentro, superando o divórcio, típico de nossa sociedade, entre objetividade e subjetividade. Ora, defende-se que o processo educacional não é alcançado unicamente através da soma das qualidades técnicas do sujeito, da fidelidade ao modelo econômico e da satisfação, mas se 
constrói no desenvolvimento do ser humano. Ou seja, o grande papel da educação, qualidade indispensável para que os humanos atinjam esta condição, é desenvolver o senso ético do educando.

Por ser um complexo humano, a educação nunca se impõe sozinha, mas é a soma de uma série de outros componentes, que são também indispensáveis indicadores do progresso em educação. Entre eles destacam-se: utilização dos meios e técnicas de transmissão e problematização do conhecimento; o aspecto organizacional (infraestruturas, práticas pedagógicas) e; e papel humano dos atores da atividade pedagógica. Porém, o progresso na educação só poderá ser alcançado pelo critério ético do plenamente humano aliado ao perfeito entrosamento entre o perfeito domínio da técnica de ensino, da organização apropriada, da excelência das atividades pedagógicoadministrativas e da qualidade das inter-relações humanas, consideradas entre si.

A questão que surge disto é a seguinte: que tipo de reflexão fornece a ética? A primeira certeza que o eticista deve ter presente quando se propõe a fazer uma investigação ética, isto é, uma análise racional sobre o comportamento humano é de que a ética não é uma reflexão desvinculada do mundo circundante: ela é uma teorização sobre a vida e a educação prática e cotidiana.

A ética é uma reflexão que permite ao ser humano comparar a vida real, o seu cotidiano, o seu dia-a-dia, enfim o seu contexto histórico, social, econômico, cultural e educacional com as possibilidades reais e ideais. Portanto, quando se fala em ética, tem-se presente uma reflexão sobre a vida real, situada numa circunstância concreta e singular.

A partir dessas ideias preliminares, torna-se oportuna e necessária uma reflexão crítica sobre a ética na vida do professor (IMBERT, 2001). Quem é o professor? Qual é a sua identidade? Qual é o papel social atribuído a ele pela sociedade contemporânea? Entende-se que ser professor não é algo que ocorre ocasionalmente, por algum acidente, mas pressupõe uma escolha e um investimento humano, em prol da tarefa do ensino como uma profissão. Ensinar é o trabalho para o qual o professor se sente preparado humana e intelectualmente, e contribui com a sociedade.

Todas as profissões estão diretamente relacionadas com as virtudes. As virtudes profissionais uma vez bem executadas tornam o profissional virtuoso, ou ainda, só podem ser bem executadas quando o profissional é virtuoso. Etimologicamente, no grego, a palavra "virtude" significa qualidade destacada, uma força, uma capacidade superior, enfim uma "excelência" ou distinção frente ao que é comum e trivial. 
A virtude assume, por conseguinte, ao longo da história, um sentido tipicamente ético, concentrou-se sobre o fazer bem as coisas, em suma, fazer o Bem. Nesse sentido, as virtudes são figuras concretas, formas de comportamento estabelecidas dentro de certas tradições, culturas e corporações, e estas culturas e corporações desenvolveram e continuam a desenvolver padrões de qualidade que refletem sobre as responsabilidades que tornam um profissional melhor que outro, ou seja, mais próximo do ideal daquela profissão.

Essa pequena reflexão nos permite identificar e perceber um problema que, muitas vezes à luz de uma rápida análise, se mostra indetectável e imperceptível: até que ponto a profissão de professor está institucionalizada? Uma profissão estabelecida costuma desenvolver certas regras e responsabilidades para com a sociedade, clientes, colegas e classe profissional, que defendem as boas práticas, ou seja, as virtudes profissionais e, com isso, salvaguardam o bom nome da profissão. Enfim, quais são as virtudes, os deveres e as responsabilidades que se deve esperar de um professor?

\section{CONSIDERAÇÕES FINAIS: BIOÉTICA E PRÁTICA DOCENTE}

Uma possível tentativa de resposta propositiva, ao questionamento colocado anteriormente, poderia ser esboçada a partir da área da Ética aplicada, mais especificamente da Bioética, que tem produzido uma reflexão muita rica e profunda, nos últimos trinta anos. A Bioética é uma reflexão que faz uma ponte entre os conhecimentos científicos e a cultura humanística: ciências humanas; sociais aplicadas; tecnológicas e os valores filosóficos (BEAUCHAMP; CHILDRESS, 2002). Ora, intenciona-se extrair da Bioética em especial de seus princípios: autonomia; não maleficência; beneficência e justiça - algumas perspectivas para a reflexão sobre a virtude e o trabalho docente.

Foi com Kant que se firmou a ideia de que a ética é a esfera do universal, e que o bom critério da ética é a possibilidade de universalização de suas máximas (KANT, 1997). O formalismo kantiano é, ainda que monológico, completado com a perspectivas da ética do discurso, onde a argumentação racional se mostra em suas formas dialógicas, que buscam respeitar os interesses de todos os atingidos.

O princípio do respeito pela dignidade da pessoa humana contém uma formulação ética bem próxima da maneira contemporânea de pensar e agir. Kant já dizia que não se pode tratar a humanidade, em nós ou nos outros, apenas como um meio, mas que é preciso tratá-la como 'fim em si mesma' (KANT, 1997). Isto significa dizer que os estudantes jamais podem ser encarados ou 
tratados como um meio ou cobaias dos professores. Nessa mesma perspectiva, poder-se-ia avançar e perguntar o que significa na prática tratar os colegas professores, diretores, funcionários, bibliotecários, porteiros e, assim por diante, com respeito e dignamente? Significa aceitar, tolerar e até mesmo apreciar as diferenças do Outro.

O que significa, na prática, respeitar os estudantes em sua dignidade? Significa ver neles as pessoas maduras que ainda não são e nem precisam ser, mas que logo adiante poderão ser; amá-los, investir, dedicar-se, sentir carinho, acreditar que eles poderão transformar-se em grandes personalidades; dizer 'isto eu não sei, mas vou estudar e na próxima aula trago uma boa pista'; objetividade científica, respeito pela matéria, verdade que precisa ser conhecida; o respeito precisa estar presente na estruturação de um currículo, de uma disciplina, de um plano de ensino e na metodologia de sua execução; e, enfim, o respeito precisa se manifestar até nos corredores, na convivência do dia-a-dia, na cortesia.

E o princípio da justiça, o que exige dos professores? Exige necessária e obviamente, muita objetividade da hora da avaliação. Não se pode, enquanto educadores, se deixar arrastar pelos preconceitos, estereótipos; acreditar que o estudante pode sempre surpreender o seu professor, pode crescer e desenvolver-se cognitiva e afetivamente e, aliás, é exatamente para isso que está diante do educador, para progredir em todos os sentidos; é também uma questão de justiça compartilhar as alegrias e descobertas que se faz em cada matéria e assunto. Um adágio já dizia: o bem quer difundir-se; se é bem, é bom que seja compartilhado (ARISTÓTELES, 2001). Dessa forma, em todas as áreas do conhecimento, o bom professor deve ser um entusiasta em comunicar seus conhecimentos aos outros, ou seja, o bom professor é o professor virtuoso; em uma época em que o conhecimento evolui muito rapidamente, o professor deve apostar mais nas habilidades reflexivocrítica do que na informação. A transmissão do método de trabalho e de pesquisa é mais formativa do que o assegurar-se de que o estudante memorizou a informação que se tentou transmitir.

O princípio da não maleficência enfatiza que se deve fazer o bem e evitar o mal. É bastante evidente, que os professores no Brasil são desvalorizados, mas nem por isso se deve transmitir aos estudantes essas sequelas e frustrações, isto é, deve-se saber separar o trabalho do salário, para não se rebaixar o trabalho à altura do salário, até porque as pessoas são pagas de várias formas: não só com dinheiro. Entende-se que os professores têm o direito de perceber uma remuneração digna, mas não condicionar ao pagamento o seu melhor desempenho, não se deve transmitir aos estudantes as consequências dessa insatisfação. 
Em nome do princípio da Beneficência, além de não fazer o mal aos colegas e estudantes, tem-se de fazer o bem. Qual o maior bem a ser feito em educação? Transmitir-lhes, com grande amizade, com carinho respeitoso e com respeito carinhoso, os resultados das pesquisas desenvolvidas. O professor deve ensinar as verdades que realmente ama, e deveria ensiná-las por amor, ou pelo menos por respeito aos estudantes.

Acredita-se que essa aproximação reflexiva dos princípios filosóficos da Bioética à prática educativa, poderá possibilitar uma resignificação dos valores e virtudes fundamentais na prática docente. Esse parece ser o grande desafio que os educadores têm pela frente, ou seja, resgatar a importância dos valores éticos no campo da educação.

O que caracteriza o tempo presente é a transitoriedade e o respeito incondicional à pessoa humana em sua singularidade. Nesse sentido, requerem-se profissionais críticos, criativos, que participem e empreendam. Um profissional que tenha uma visão global do mundo da cultura e uma consciência dos valores da vida, do seu papel enquanto agente de mudança, não sendo apenas um agente do processo de construção de conhecimentos, mas um cidadão crítico e participativo.

A presente reflexão tentou apresentar a Bioética como fundamento da educação e da própria ciência, no sentido de propiciar ao estudante as posições a serem tomadas no seu processo de escolha, na sua postura social. Com a clarificação dos valores emergentes de uma sociedade, com a reflexão dos princípios éticos que a dimensionam e a estruturam, o indivíduo poderá ter melhores condições para refletir e discutir os valores da verdade, da liberdade e da responsabilidade.

Portanto, a educação, estando comprometida com o humano, conduzirá ao entendimento do que seja e qual a razão de ser dos conhecimentos, valores, crenças, mitos, desejos, interesses e necessidades. A educação, acompanhando e interferindo no mundo da vida, poderá e deverá promover a dimensão ética, necessária à transformação individual e social. O grande papel da educação ética, em um mundo pós-moderno, em que os valores e as instituições sociais estão em crise, deve ser o de gestar as condições para um pensar crítico e reflexivo, um agir consciente e responsável, e, sobretudo, para o estabelecimento de uma convivência sadia com os demais em prol da construção de uma sociedade justa, igualitária e humana. 


\section{REFERÊNCIAS}

ALENCAR, C. Educar é humanizar. In: GENTILI, P.; ALENCAR, C. (Org.). Educar na esperança em tempos de desencanto. Petrópolis: Vozes, 2001.

ANJOS, M. F. Bioética: abrangência e dinamismo. In: BARCHIFONTAINE, C.P.; PESSINI, L. (Orgs.). Bioética: alguns desafios. São Paulo: Loyola, 2001. p. 17-34.

ARISTÓTELES. Ética a Nicômacos. Brasília: Editora UnB, 2001.

ARENDT, H. A condição humana. Rio de Janeiro: Forense Universitária, 2003.

BEAUCHAMP, T. L.; CHILDRESS, J. F. Princípios de ética biomédica. São Paulo: Loyola, 2002.

CLOTET, J. Bioética: uma aproximação. Porto alegre: EDUPUC, 2003.

CORTINA. A. Ética civil e religião. São Paulo: Paulinas, 1996.

DURAND, G. Introdução geral a bioética: história, conceitos e instrumentos. São Paulo: Loyola, 2003.

DURAND, G. Natureza da bioética. São Paulo: Paulus, 1995.

FREIRE, P. Pedagogia da autonomia: saberes necessários à prática educativa. São Paulo: Paz e Terra, 1996.

GARRAFA, V.; COSTA, S. B. F. (Orgs.). A bioética no século XXI. Brasília: Editora da UnB, 2000.

IMBERT, F. A questão da ética no campo educativo. Petrópolis, RJ: Vozes, 2001.

KANT, I. Fundamentação da metafísica dos costumes. Lisboa: Edições 70, 1997.

. Sobre a pedagogia. Piracicaba: Editora Unimep, 1999.

POTTER, V. Bioethics, bridge to the future. Englewood Cliffs, NJ: Prentice Hall, 1971.

. Bioética Global e Sobrevivência Humana. In: BARCHIFONTAINE C.; PESSINI, L. Bioética: alguns desafios. São Paulo: Loyola, 2001.

SAVIANI, D. Educação: do senso comum à consciência filosófica. Campinas, SP: Autores Associados, 2002.

VÁZQUEZ, A. S. Ética. Rio de Janeiro: Civilização Brasileira, 2002. 


\section{RESUMO}

O texto contempla uma abordagem filosófica e destaca a importância da ética no campo da educação, tomando como referência os principais valores bioéticos. Parte-se de uma reflexão crítica sobre os fundamentos da educação, tendo em vista uma formação ética, comprometida com os valores e a construção de uma subjetividade fraterna e cidadã. Sustenta-se que a educação não pode servir apenas para ensinar a ler, escrever e contar, senão para formar homens que sejam sujeitos de sua história, que tenham a possibilidade de desenvolver suas potencialidades e produzir novas condições para ler e compreender o mundo. Defende-se que o papel da educação, fundada em valores bioéticos, é o de gestar as condições para um pensar crítico e reflexivo; um agir livre, consciente e responsável; e um conviver cuidadoso com os demais seres e, sobretudo, voltado para a construção de uma sociedade ética: justa e pacífica.

Palavras-chave: Ética; Educação; Bioética; Liberdade; Justiça.

THE (BIO)ETHICS VALUES IN LIFE AND IN THE TEACHER PRACTICE

\section{ABSTRACT}

The text contemplates a philosophical approach and highlights the importance of ethics in the field of education, taking by reference to the major bioethical values. It is part of a critical reflection on the foundations of education, with a view ethical education committed to the values and the construction of a fraternal and civic subjectivity. It is sustains that education can not only serve to teach reading, write and count, but for forming men who are subjects of their own history, they have the possibility to develop their potential and produce new conditions for reading and understanding the world. It is defends that the role of education, founded in bioethical values, is to gestate the conditions for a critical and reflexive think; one act free, conscious and responsible; and careful coexist with the other beings and, above all, focused on building an ethical society: just and peaceful.

Keywords: Ethics; Education; Bioethics; Freedom; Well; Justice.

Submetido maio 2016

Aprovado ago. 2016 